Gut, 1984, 25, 1103-1106

\title{
Endoscopic measurement of oesophageal transmucosal potential difference in reflux oesophagitis
}

\author{
B J COLlins, R J McFARLAND, J M SLOAN, AND A H G LOVE \\ From the Queen's University, Belfast, The Royal Victoria Hospital, Belfast and The Ulster Hospital, Belfast
}

SUMMARY Oesophageal transmucosal potential difference (PD) was measured in 76 patients during endoscopy. Twelve patients with no symptoms of gastro-oesophageal reflux, and normal oesophageal appearance on endoscopy and mucosal biopsy had a PD of $-18 \cdot 3 \pm 3 \cdot 8 \mathrm{mV}$ (mean \pm SD). Thirty three patients had reflux symptoms but the oesophagus appeared normal at endoscopy. Eighteen of these patients had reflux change on oesophageal suction biopsies and the $\mathrm{PD}$ in the same region of the oesophagus in this group was $-18 \cdot 1 \pm 7 \cdot 5 \mathrm{mV}$. In 15 of the patients, mucosal biopsies were normal and the PD in this group was $-18 \cdot 8 \pm 9.9 \mathrm{mV}$. Thirty one patients had erosive oesophagitis and PD values in this group were markedly reduced. Twenty seven of these patients had PD values $<-10 \mathrm{mV}$. We conclude that PD measured by our technique is abnormal in erosive oesophagitis but that it is of no value in the diagnosis of mild mucosal damage in patients with reflux symptoms when endoscopic findings are normal.

Endoscopic examination of the oesophagus is normal in many patients with established gastrooesophageal reflux. ${ }^{1}$ Mucosal biopsy increases the diagnostic yield but suction biopsies are usually necessary to obtain adequate tissue for histological assessment. $^{2-4}$

Khamis and colleagues have suggested that measurement of oesophageal transmucosal potential difference at endoscopy is a simple, rapid and sensitive method of detecting oesophageal mucosal damage. ${ }^{5}$ Many investigators have observed a fall in oesophageal or gastric PD in the presence of irritating agents such as bile acids, salicylates, and alcohol. ${ }^{6-9}$ These observations support the concept that oesophageal PD reflects mucosal integrity. There have been no studies, however, to confirm the diagnostic value of oesophageal PD measurement during endoscopy.

We have established a simple method of PD measurement during routine endoscopy ${ }^{10}$ and have assessed its value in the diagnosis of reflux oesophagitis.

\section{Methods}

PATIENTS

Seventy six patients were studied. All had been

Address for correspondence: Dr B J Collins. Department of Medicine. Institute of Clinical Science, Grosvenor Road, Belfast BT12 6BJ

Received for publication 6 January 1984 referred to the gastroenterology units at the Ulster Hospital, Dundonald or the Royal Victoria Hospital, Belfast, for the evaluation of gastrointestinal symptoms.

Oesophageal transmucosal PD was measured during routine upper gastrointestinal endoscopy. Informed consent was obtained in every case. Before endoscopy, fasting patients were given a spray of $1 \%$ lignocaine to the pharynx and a combination of diazepam and fentanyl intravenously, sufficient to produce ptosis and slurring of speech.

Equipment fór PD measurement was similar to that described by other investigators. ${ }^{511}$ Saline-agar electrolyte bridges were used rather than saturated $\mathrm{KCl}$-agar bridges as there is evidence that the latter may produce unstable and variable readings because of the irritating effect of $\mathrm{KCl}$ on oesophageal mucosa. ${ }^{12}$

Two electrolyte bridges, consisting of polyethylene tubing (external diameter $2 \mathrm{~mm}$ ) filled with $154 \mathrm{mmol} / \mathrm{l} \mathrm{NaCl}$ in $3 \%$ agar gel, led to two beakers, each containing $154 \mathrm{mmol} / \mathrm{l} \mathrm{NaCl}$ solution and a Pye Unicam calomel electrode (Type 303). The two calomel electrodes in the circuit were connected to a battery operated digital millivoltmeter (Pye Unicam PW 9411) which gave a digital reading of the PD with polarity.

At the beginning and end of each study, the offset potential between the two halves of the circuit was 
assessed by inserting the exploring ends of both electrolyte bridges into the same saline solution. Such offset potentials were usually $1 \mathrm{mV}$ or less, and remained constant throughout the study. They were subtracted from subsequent PD readings.

The reference electrolyte bridge was applied to a skin bleb on the volar aspect of the patient's forearm. The bleb was formed by intradermal injection of $0 \cdot 1-0.2 \mathrm{ml} 154 \mathrm{mmol} / 1 \mathrm{NaCl}$. This technique has been shown to virtually abolish the skin blood PD. ${ }^{10} 13$

The biopsy channel of the endoscope (Olympus GIF-D3 or GIF-Q) and the lower half of the oesophagus were washed with $20 \mathrm{ml}$ normal saline before recording PD. The exploring electrolyte bridge was passed through the biopsy channel and applied gently to the oesophageal mucosa, $5 \mathrm{~cm}$ above the oesophagogastric junction. Contact with the mucosa was maintained for 1 minute until a stable PD reading was obtained. In patients with erosive oesophagitis, the electrolyte bridge was applied directly over the eroded mucosal surface.

After endoscopy, suction biopsies were taken with a Quinton suction tube at a site $5 \mathrm{~cm}$ above the oesophagogastric junction. One to five biopsies were obtained from each patient. Histological assessment of haematoxylin and eosin stained slides was carried out by a colleague (JS) who had no knowledge of the endoscopic appearance or potential difference measurement. Biopsies were classified according to the criteria of basal zone hyperplasia and papillary elongation described by Ismail-Beigi. ${ }^{3}$

\section{Results}

Patients were classified into four groups according to their symptoms, endoscopic, and biopsy findings.

\section{GROUP 1}

Twelve patients (mean age 40.9 years) had no reflux symptoms. Epigastric pain was the presenting complaint and no abnormality was detected on endoscopic examination of the oesophagus. Oesophageal mucosal biopsies were all normal. Potential difference in this group was $-18 \cdot 3 \pm 3 \cdot 8$ $\mathrm{mV}$ (mean $\pm \mathrm{SD}$ ) (Figure). A normal range for oesophageal PD of $-10.7 \mathrm{mV}$ to $-25.9 \mathrm{mV}$ was calculated from the mean $\mathrm{PD} \pm 2$ standard deviations in this group.

\section{GROUP 2}

Fifteen patients (mean age 43.5 years) complained of heartburn with or without regurgitation. The oesophagus was normal at endoscopy and mucosal biopsies were normal. A wide range of PD values was found in this group $(-2 \mathrm{mV}$ to $-36 \mathrm{mV})$ although the mean value was $-18 \cdot 8 \pm 9.9 \mathrm{mV}( \pm \mathrm{SD})$ (Figure). Nine patients $(60 \%)$ had PD readings within the normal range.

\section{GROUP 3}

Eighteen patients (mean age 42.5 years) with reflux symptoms had a normal oesophageal appearance at endoscopy although one or more mucosal biopsies showed the features of reflux change (basal zone hyperplasia and papillary elongation). Again, a wide range of $P D$ values was recorded $(-6 \mathrm{mV}$ to -31 $\mathrm{mV})$, and the mean PD was $-18 \cdot 1 \pm 7.5 \mathrm{mV}( \pm \mathrm{SD})$ (Figure). Eleven patients $(61 \%)$ had PD readings within the normal range.

Potential difference values in groups 2 and 3 followed a normal distribution, and statistical assessment revealed no significant difference between these groups. (Student's $t$ test).

\section{GROUP 4}

Thirty one patients (mean age 54.6 years) with reflux symptoms had linear erosions in the lower third of the oesophagus. The PD in this group was markedly reduced towards a reading of zero. Values did not follow a normal distribution and thus the

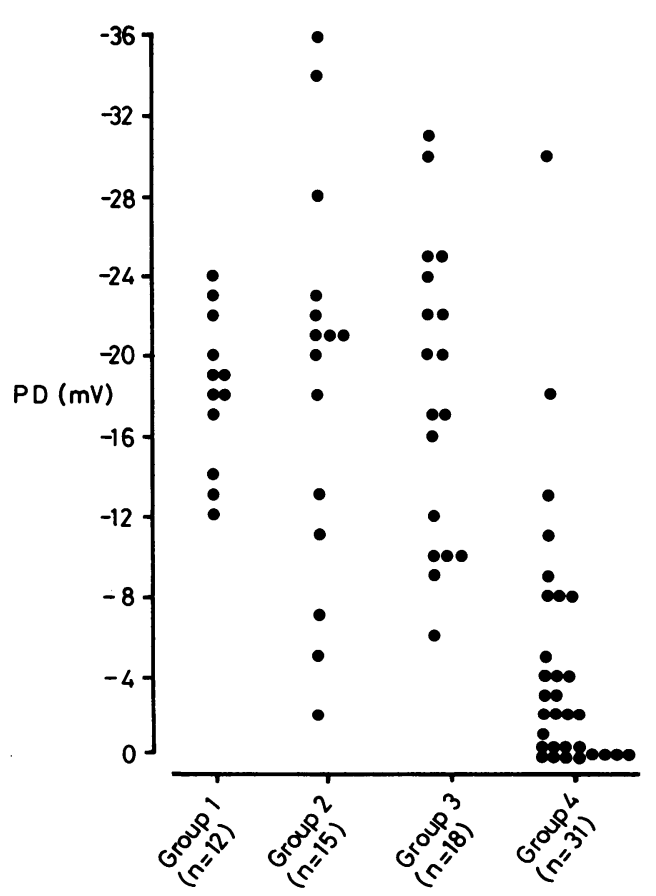

Figure Oesophageal transmucosal potential difference readings. 
mean value and standard deviation are not reported. Twenty seven patients $(87 \%)$ had a PD of $<-10 \cdot 7$ $\mathrm{mV}$. Twelve of these had a PD of zero. In no patient was a positive value for PD recorded (Figure).

\section{Discussion}

Although oesophageal PD measurements were reported by Rovelstad and colleagues in $1952^{14}$ their use in clinical studies has been limited. The earliest description of PD measurement in oesophageal disease was by Beck and Hernandez in $1969 .{ }^{15}$ They described a positive reading in the normal oesophagus and noted a fall towards zero over mucosal ulcerations. Khamis and colleagues in 1978 measured oesophageal PD during endoscopy and found a mean PD of $-14 \mathrm{mV}$ in 10 patients with normal mucosal biopsies and $+9.4 \mathrm{mV}$ in nine with biopsies showing reflux change. ${ }^{5}$

The detection of a positive value for PD either in the normal or diseased oesophagus cannot be reconciled with the electrophysiology of $\mathrm{PD}$ formation. Active transport of $\mathrm{Na}+$ ions from mucosa to serosa produces a negative PD across the wall of the oesophagus. ${ }^{16}$ Mucosal damage may decrease the PD by impairing the active transport of ions, and by reducing the resistance of the tissue through which the ions are transported. A reversal of ion flow to produce a positive charge on the luminal side of the oesophageal wall is not a recognised sequel to mucosal damage.

The choice of reference electrode site determines the accuracy of PD readings. The bloodstream has been shown to be equipotential to the serosa of the gastrointestinal tract. ${ }^{17}$ whereas a large and variable negative PD exists between skin and blood. ${ }^{18}$ Beck and Hernandez used scarified skin as a reference site in their study and Khamis and colleagues applied cotton wool soaked in $\mathrm{KCl}$ to the skin of the forearm to reduce the skin-blood PD of their reference site. ${ }^{155}$ Although we used saline-agar electrolyte bridges rather than $\mathrm{KCl}$-agar, we were unable to confirm that either of these methods effectively abolished the skin-blood PD. ${ }^{10}$ Thus, it is likely that the reporting of positive values for oesophageal PD reflects the use of reference electrode sites on the skin where the skin-blood PD has not been adequately reduced.

A recent report described PD measurement in oesophageal disease, using flowing $\mathrm{NaCl}$ electrolyte bridges during manometric studies. ${ }^{19}$ A marked reduction in $\mathrm{PD}$ towards zero was found in patients with erosive oesophagitis. Furthermore, normal PD values were recorded in patients with reflux symptoms and a normal endoscopic appearance, in whom biopsies revealed no neutrophil infiltration.
Grasp biopsies were used in that study and tissue was not adequate for assessment of the more sensitive histological criteria of Ismail-Beigi. The observations are, however, in agreement with our own findings using an endoscopic technique.

Eckardt and Adami also used flowing saline electrolyte bridges in the measurement of PD in patients with reflux symptoms and normal endoscopic findings. ${ }^{20}$ They studied only nine patients but recorded a more negative PD than in control subjects. In our own study a very wide range of PD values was recorded in patients with reflux symptoms, although mean values were almost identical to those of our controls. It is possible that a sampling error explains the result of the German study. We speculate that the wide range of PD values in our patients may reflect the focal distribution of histological changes associated with gastro-oesophageal reflux. It is possible that basal zone hyperplasia, a feature of reflux oesophagitis, may increase the resistance of the oesophageal mucosa and contribute to a more negative PD, whereas the dilatation of intraepithelial blood vessels which is detected in gastro-oesophageal reflux ${ }^{21}$ may reduce mucosal resistance and hence the transmucosal PD.

The focal nature of oesophagitis reduces the diagnostic value of a negative mucosal biopsy in the assessment of a patient with reflux symptoms and normal endoscopic appearance. Thus, the comparison of PD values in such patients who have positive or negative biopsies is of limited value. Our study has shown, however, such a wide range of PD readings in those patients with positive biopsies that no diagnostic application of the technique is likely. The detection of abnormal PD in the patients with erosive oesophagitis is of scientific interest but it does not enhance the diagnostic accuracy of endoscopy.

B J Collins was in receipt of a Royal Victoria Hospital Research Fellowship during the period of this work.

\section{References}

1 Johnson LF, Demeester TR, Haggitt RC. Endoscopic signs for gastro-esophageal reflux objectively evaluated. Gastrointest Endosc 1976; 22: 151-5.

2 Behar J, Shearan DC. Histological abnormalities in reflux oesophagitis. Arch Pathol 1975; 99: 387-91.

3 Ismail-Beigi F, Horton PF, Pope II CE. Histological consequences of gastroesophageal reflux in man. Gastroenterology 1970; 58:163-74. 
4 Komorowski RA, Leinicke JA. Comparison of fibreoptic endoscope and Quinton tube esophageal biopsies in esophagitis. Gastrointest Endosc 1978; 24: 154-5.

5 Khamis B, Kennedy C, Finucane J, Doyle JS. Transmucosal potential difference; diagnostic value in gastro-oesophageal reflux. Gut 1978; 19: 396-8.

6 Black RB, Rhodes J, Hole D. Measurement of bile damage to the gastric mucosa. The relation between the electrical potential difference and transmucosal movement of hydrogen and sodium ion. Dig Dis 1973; 18: 411-5.

7 Bowen BK, Krause WJ, Ivey KJ. Effect of sodium bicarbonate on aspirin-induced damage and potential difference changes in human gastric mucosa. $\mathrm{Br}$ Med J 1977; 2: 1052-5.

8 Chung RSK, Johnson GM, Denbesten L. Effect of sodium taurocholate and ethanol on hydrogen ion absorption in rabbit esophagus. Dig Dis 1977; 22: 582-8.

9 Murray HS, Strottman MP, Cooke AR. Effect of several drugs on gastric potential difference in man. $\mathrm{Br}$ Med J 1974; 1: 19-21.

10 Collins BJ, Spence RAJ, McFarland RJ, Parks TG, Love AHG. Reference electrode sites for potential difference measurements in the gastrointestinal tract. Endoscopy 1983; 15: 319-21.

11 Grantham RN, Code CF, Schlegel JF. Reference electrode sites in determination of potential difference across the gastro-esophageal mucosal junction. Mayo Clin Proc 1970; 45: 265-74.

12 Hernandez NA, Beck IT. Gastroesophageal transmural potential difference measured by a new constant infusion method. The effect of skin scarification on this potential difference. Am J Dig Dis 1969; 14: 206-16.

13 Archampong EQ, Edmonds CJ. Effect of luminal ions on the transepithelial electrical potential difference of human rectum. Gut 1972; 13: 559-65.

14 Rovelstad RA, Owen CA, Magath TB. Factors influencing the continuous recording of in situ $\mathrm{pH}$ of gastric and duodenal contents. Gastroenterology 1952; 20: 609-24.

15 Beck IT, Hernandez NA. Transmucosal potential difference in patients with hiatus hernia and oesophageal ulcer. Gut 1969; 10: 469-76.

16 Turner KS, Powell DW, Carney CN, Orlando RC, Bozymski EM. Transmural electrical potential difference in the mammalian esophagus in vivo. Gastroenterology 1978; 75: 286-91.

17 Geall MG, Code CF, McIlrath DC, Summerskill WHJ. Measurement of gastrointestinal transmural electric potential difference in man. Gut 1970; 11: 34-7.

18 Andersson S, Grossman MI. Profile of $\mathrm{pH}$, pressure and potential difference at gastroduodenal junction in man. Gastroenterology 1965; 49: 364-71.

19 Orlando RC, Powell DW, Bryson JC et al. Esophageal potential difference measurements in esophageal disease. Gastroenterology 1982; 83: 1026-32.

20 Eckardt VF, Adami B. Esophageal transmural potential difference in patients with symptomatic gastroesophageal reflux. Klin Wochenschr 1980; 58: 293-7.

21 Geboes K, Desmet V, Vantrappen G, Mebis J. Vascular changes in the esophageal mucosa. An early histological sign of esophagitis. Gastrointest Endosc 1980; 26: 29-32. 